\title{
Indications of Lefort osteotomies for facial deformities induced by craniosynostosis
}

\section{GLEIZAL Arnaud a,b,c , DI ROCCO Frederico ${ }^{\text {c,d }}$, CHAUVEL-PICARD Julie ${ }^{\text {a,c, }}$}

a) Department of Pediatric Cranio-Maxillo-Facial Surgery, Hôpital Femme Mère Enfant, 59 Boulevard Pinel, 69677 BRON, France

b) INSERM, National Institute of Health and Medical Research, Unit 1032, 151 Cours Albert Thomas 69424 LYON CEDEX 03, France

c) Université Claude Bernard Lyon 1, 43 Boulevard du 11 Novembre 1918, 69100 Villeurbanne

d) Department of Pediatric Neurosurgery, Hôpital Femme Mère Enfant, 59 Boulevard Pinel, 69677 BRON, France

Corresponding Author :

Dr CHAUVEL-PICARD Julie

Department of Pediatric Cranio-Maxillo-Facial Surgery

Hôpital Femme Mère Enfant

59 Boulevard Pinel

69677 BRON, France

Mail : Julie.chauvelpicard@gmail.com

$\underline{\text { Phone : } 33(0) 624282186}$ 


\section{Introduction}

Craniofacial growth generally follows a cranio-caudal pattern with an initial rapid calvarial growth during infancy, followed by orbital and midface growth in the first decade and mandibular growth in adolescence. Craniosynostosis is defined as the premature fusion of one or more cranial sutures. According to Virchow's concept, fusion of a cranial vault suture restricts growth perpendicular to it but "extra" growth parallel to produce an often typical skull deformity. More recent theories invoke the action of a "functional matrix" that comprises bone, but also the adjacent duramater and other soft tissues [1]. Craniosynostosis is defined as the premature fusion of one or more cranial sutures. There are two different groups of craniosynostosis: syndromic and non syndromic craniosynostosis.

Both can induce facial and maxillary growth abnormalities. The genetically determined syndromic craniosynostoses are a heterogeneous group of conditions usually associated with gain-of-function mutations, often including predominantly the fibroblast growth factor receptor (FGFR) family of genes involved in bone and cartilage development. Midface hypoplasia is generally very marked. Non syndromic craniosynostosis can also induced dentofacial abnormalities because of modifications of basal skull angulation.

Both can induce skeletal class III by maxillary hypoplasia. Maxillary hypoplasias may be classified as:

- Supra-apical maxillary hypoplasia (Figure 1a, Figure 1b)

- Nasomaxillary hypoplasia (Figure 2a, 2b)

- Total mid facial hypoplasia (Figure 3)

Intermediate forms also exist. 
Clinical analysis of midface hypoplasia is very important to allow an adapted treatment. Scleral show, exorbitism, zygomatic hypoplasia, nasal bone projection, nasolabial angle, nasolabial fold should be examinated and described very carefully.

After a meticulous clinical and radiological analysis, different type of facial osteotomies could be proposed.

The surgical treatment alternatives for major midfacial sagittal deficiencies consist of Le Fort I, II or III with conventional osteotomies or with distraction osteogenesis.

Since the first description of the LeFort III osteotomy by Tessier in 1967, a variety of operations have been designed to correct combined midface and maxillary deficiency $[2,3]$. These approaches have included: high LeFort I osteotomies [4], LeFort I osteotomies with zygomatic extensions [5], modified LeFort I (maxillary-zygomatic) osteotomies [6], quadrangular LeFort II osteotomies [7-9], pyramidal LeFort II osteotomies [10,11], LeFort I or LeFort III osteotomies and zygomatic augmentation with onlay bone grafts $[4,12,13]$, subcranial LeFort III osteotomies [14], and modified LeFort III osteotomies including: nasomalar [15], nasomaxillary [4], maxillary-malar [4,16], oblique [17,18] and simultaneous LeFort III/LeFort I osteotomies [2,19,20].

All these techniques can be applied using distraction osteogenesis or one step advancement surgery.

We deliberately chose not to talk about distraction, frontofacial advancement in this article and to focus on the different Lefort osteotomy techniques except the Lefort I osteotomy which is detailed in an other article in the journal. 


\section{Lefort II and modified Lefort II osteotomies (Figures 4, 5, 6)}

Henderson and Jackson presented a landmark paper in 1973 regarding Lefort II osteotomy for the treatment of patients with nasomaxillary hypoplasia [10]. They described four types of nasomaxillary hypoplasia in which this procedure is indicated.

They are:

- Nasomaxillary hypoplasia involving the dentoalveolar segment

- Nasomaxillary hypoplasia excluding the dentoalveolar segment

- Nasomaxillary hypoplasia associated with cleft palate

- Nasomaxillary hypoplasia associated with pan facial problems

Nasomaxillary hypoplasia involving the dentoalveolar segment is characterized by recession of the nasal bridge producing a short nose, upturned nose or a recessed nose at the tip. The whole nasal skeleton is insufficiently projected forwards. Hypoplasia of the infraorbital rim and adjacent bone leading to increased inferior scleral exposure. The occlusion is abnormal. Nasomaxillary hypoplasia excluding the dentoalveolar segment, also known, as Binders syndrome is very similar to type 1 nasomaxillary hypoplasia except that the dentoalveolar segment is normally related to the cranial base.

Nasomaxillary hypoplasia associated with panfacial problem is a heterogeneous group, which exhibits a degree of nasomaxillary hypoplasia in association with other skeletal disproportions, most commonly mandibular protrusion or progenia or both. The combined defect produces an unsightly 'sloping face' deformity, which can be adequately corrected usually by bimaxillary jaw correction.

Clinically, nasal bone defect of projection, nasal rim hypoplasia, inferior rim hypoplasia with normal zygomatic position are found. 
The original classic Lefort 2 procedure is very rarely performed by oral and maxillofacial surgeons as most of the mid face deficient patients require more lateral infraorbital rim and zygoma augmentation.

If nasal bone is in a good position, most of the time quadrangular Lefort 2 is the preferred procedure.

The intraoral quadrangular Le Fort II osteotomy as initially described by Keller and Sather in 1987 has proved to be a suitable method for correction of midfacial deficiency with flattening of the suborbital areas but a normal projection of the nose [8][21].

Surgery is advised when skeletal maturity has been reached after puberty and it can then be performed for relative functional and esthetic reasons. The surgeon should always allow for an individual, patient based approach towards the best possible treatment.

\section{Lefort III and modified Lefort III osteotomies}

Advancement of the midface on the LeFort III level is indicated in those syndromes that include midface hypoplasia involving the nasal and zygomatic complex and bony orbits, for example the CROUZON, APERT and PFEIFFER syndromes (Figure 7).

Midface hypoplasia presents with several clinical problems, most notably at the level of the airway, orbits, occlusion and facial esthetics with their associated psychosocial problems. These patients are at high risk for upper airway obstruction and undetected obstructive sleep apnea syndrome.

Midface advancement can be scheduled in the first years of life for absolute indications, such as OSAS or severe exorbitism. If the patient is only mildly afflicted, elective surgery can be postponed until skeletal maturity has been reached after puberty and it can then be performed for relative functional and esthetic reasons. The surgeon should always allow for an individual, patient based approach towards the best possible treatment. 
Initially, Gillies used the classic Le Fort III osteotomy for middle-third advancement in patients with post-traumatic side effects. Tessier modified it into types (TI, TII, and TIII), differentiating them by the projection of the malar bone and the supercilliary arches, optimizing the advancement areas depending on the needs of each case [22]. These osteotomies require a coronal approach and modify the nasofrontal angle, but not always with a proper balance and esthetic. In response to this, Obwegeser described the Le Fort III osteotomy in a "Butterfly" design, which combines the classic Le Fort I and III osteotomies without involving the nasal component, describing a coronal approach for its performance $[19,22,23]$.

LeFort III osteotomy is performed following exposure of the frontotemporal skull, lateral orbital region, nasion, zygomatic arch and the zygomatic body with a coronal incision. The anterior surface of the maxillary antrum can be approached through the gingivobuccal sulcus. Osteotomies, following the LeFort III - Tessier III design, are then made through the frontozygomatic suture, floor of the orbit, and the nasion using a piezotome. A piezotome is used to separate the vomer and ethmoid from the cranial base in the midline. The pterygomaxillary junction is separated either from the bicoronal approach or the gingivobuccal access. Rowe forceps are then used to mobilize the Le Fort III segment including a maxillary acrylic plate to prevent unwanted fracture of the maxilla. Mobilization of the midface is an extensive procedure, carrying with it a high degree of morbidity in blood loss. Surgeons have been looking for less invasive techniques to limit morbidity. (Figures 8 , 9) Advancement of LeFort III can reach $1 \mathrm{~cm}$ and osteosynthesis with miniplates is performed. Bone grafts are usually placed in osteotomies to facilitate bone healing. If the advancement indication is greater than $1 \mathrm{~cm}$, the distraction is indicated. Indeed, the strength of the soft tissues prevents advancing more than $1 \mathrm{~cm}$. 
Several variations of the original Lefort III osteotomy have been described. (Figure 10)

Kufner's presented a modification that is used to correct deficiencies of midface projection that do not involve the nasal subunit. This modification involves an osteotomy through the zygoma and lateral orbital rim with the superior extension adjusted to the amount of lateral orbital rim deficiency and an oblique osteotomy across the floor of the orbit through the inferior orbital fissure and through the maxilla to the lateral wall of the nasal cavity, leaving the nose in its original position. Because the modified Le Fort III changes midface and orbital rim projection, it has the ability to influence the appearance of the periorbital region without alternating the projection or length of the nasal bridge.

The Modified Oblique LeFort III, described by Sanchez et al, was designed for patients without syndromic midface alterations having maxillomalar hypoplasia and a normal nasal projection therefore the osteotomy does not affect positioning of the anatomical region of the nasal bones $[17,18]$. No cranial skin incision is necessary but an inferior eyelid incision should to be performed.

Another advantage in conjunction with a maxillomalar hypoplasia which can be used in the treatment of maxillary excess vertically no more than $6 \mathrm{~mm}$.

\section{Simultaneous modified LeFort III/LeFort I osteotomies (Figure 11)}

There are several problems inherent in performing single segment midface surgery.

First, it is difficult to obtain comprehensive results in occlusal correction while simultaneously correcting a hypoplastic midface deformity and maintaining bilateral symmetry of the malar prominences. Maxillomandibular occlusal corrections often involve both vertical and horizontal bony movements which may or may not coincide with the planned amount of midface movement. 
Second, patients will occasionally present with large anteroposterior dental discrepancies and request surgical correction with strict avoidance of mandibular surgery and possible lower lip paresthesia. A simultaneous LeFort III/LeFort I osteotomy can reliably achieve large midfacial movements that may obviate the need for mandibular surgery.

Finally, independent midface movements are generally performed as advancements or augmentations with or without changes in maxillary roll, pitch, and jaw and are designed to correct or to maintain midface symmetry. In cases of symmetrical midface advancement without the occlusal scheme changing, no problems should be anticipated.

However, attempting asymmetric midface advancement while also correcting: the maxillary occlusal midline, maxillary tilting, or maxillary advancement with changes in the maxillary central incisor tooth position, can be optimally corrected with simultaneous LeFort III/LeFort I osteotomies. Reports in the literature frequently describe midface surgery with separate osteotomies at the LeFort III or LeFort I level. Obwegeser in 1969 was the first to describe a simultaneous LeFort III and LeFort I [19].

\section{Distraction osteogenesis and osteotomies}

Two techniques of distraction osteogenesis are proposed: external distraction osteogenesis and internal distraction osteogenesis.

Distraction osteogenesis can be combined with Lefort II and Lefort III osteotomies if the advancement is more than $1 \mathrm{~cm}$ [24]. Indeed, an advancement of more than $1 \mathrm{~cm}$ can be difficult to manage because of the strength of the soft tissues. Distraction osteogenesis combined could be discussed in these cases.

External distraction device or internal distraction device can be used. There is not really statistical difference between these two devices [25][26]. High satisfaction was reported for 
both internal and external device for facial aesthetics and functional improvements. However, internal device reported a better quality of life and a better comfort.

The difficulty in the pose of the internal distractor device is to manage the orientation vector.

External distraction device is easier to use for physician because the orientation of the distraction can be more controlled compared to the internal distraction device.

\section{Conclusion}

Many types of Lefort II and Lefort III osteotomies have been proposed to correct midface hypoplasia.

Sometimes the results are not satisfactory. Hypoplasia may re-offend or may eventually be poorly corrected. Surgical revisions with or without distraction osteogenesis can be performed. Usually, in cases of recurrence, this is not very important and other techniques can then correct residual defects such as the use of onlay bone graft or lipofilling.

\section{Conflicts of interest :}

We have no conflicts of interest 


\section{References}

[1] Moss ML. New studies of cranial growth. Birth Defects Orig Artic Ser 1975;11:283-95.

[2] Tessier P. Total osteotomy of the middle third of the face for faciostenosis or for sequelae of Le Fort 3 fractures. Plast Reconstr Surg 1971;48:533-41. doi:10.1097/00006534-197112000-00003.

[3] Tessier P. [Treatment of facial dysmorphias in craniofacial dysostosis, Crouzon's and Apert's diseases. Total osteotomy and sagittal displacement of the facial massive. Faciostenosis, sequelae of Lefort 3 fracture]. Dtsch Zahn Mund Kieferheilkd Zentralbl Gesamte 1971;57:302-20.

[4] Epker BN, Wolford LM. Middle-third facial osteotomies: their use in the correction of acquired and developmental dentofacial and craniofacial deformities. J Oral Surg Am Dent Assoc 1965 1975;33:491-514.

[5] Kaminishi RM, Davis WH, Hochwald DA, Nelson N. Improved maxillary stability with modified Lefort I technique. J Oral Maxillofac Surg Off J Am Assoc Oral Maxillofac Surg 1983;41:203-5. doi:10.1016/0278-2391(83)90084-8.

[6] Abubaker AO, Sotereanos GC. Modified Le Fort I (maxillary-zygomatic) osteotomy: rationale, basis, and surgical technique. J Oral Maxillofac Surg Off J Am Assoc Oral Maxillofac Surg 1991;49:1089-97. doi:10.1016/0278-2391(91)90144-b.

[7] Kufner J. Four-year experience with major maxillary osteotomy for retrusion. J Oral Surg Am Dent Assoc 1965 1971;29:549-53.

[8] Keller EE, Sather AH. Intraoral quadrangular Le Fort II osteotomy. J Oral Maxillofac Surg Off J Am Assoc Oral Maxillofac Surg 1987;45:223-32. doi:10.1016/0278-2391(87)90119-4.

[9] Brouns JJ, Freihofer HP. Long-term results on the quadrangular osteotomy. Int J Oral Maxillofac Surg 1992;21:192-8.

[10] Henderson D, Jackson IT. Naso-maxillary hypoplasis--the Le Fort II osteotomy. Br J Oral Surg 1973;11:77-93.

[11] Steinhäuser EW. Variations of Le Fort II osteotomies for correction of midfacial deformities. J Maxillofac Surg 1980;8:258-65.

[12] Ousterhout DK, Vargervik K, Clark S. Stability of the maxilla after Le Fort III advancement in craniosynostosis syndromes. Cleft Palate J 1986;23 Suppl 1:91-101.

[13] Freihofer PM, Borstlap WA. Reconstruction of the zygomatic area. A comparison between osteotomy and onlay techniques. J Cranio-Maxillo-Fac Surg Off Publ Eur Assoc Cranio-Maxillo-Fac Surg 1989;17:243-8.

[14] Frost DE, Fonseca RJ, Turvey TA, Hall DJ. Cephalometric diagnosis and surgical-orthodontic correction of apertognathia. Am J Orthod 1980;78:657-69. doi:10.1016/0002-9416(80)90205-5.

[15] Epker BN, Wolford LM. Middle-third facial osteotomies: their use in the correction of 
congenital dentofacial and craniofacial deformities. J Oral Surg Am Dent Assoc 1965 1976;34:324-42.

[16] Brusati R, Sesenna E, Raffaini M. On the feasibility of intraoral maxillo-malar osteotomy. J Cranio-Maxillo-Fac Surg Off Publ Eur Assoc Cranio-Maxillo-Fac Surg 1989;17:110-5.

[17] García Y Sánchez JM, Romero Flores J, Gómez Rodríguez CL, Pacheco Rubio G, Rosales Díaz Mirón D, Hernández Miranda A. "Modified Oblique Le Fort III Osteotomy" New Concepts. J Maxillofac Oral Surg 2017;16:22-42. doi:10.1007/s12663-016-0893-7.

[18] García Y Sánchez JM, Gómez Rodríguez CL, Pacheco Rubio G. Modified Le Fort III Osteotomy: Different Applications. J Maxillofac Oral Surg 2018;17:218-27. doi:10.1007/s12663-017-1021-z.

[19] Obwegeser HL. Surgical correction of small or retrodisplaced maxillae. The "dish-face" deformity. Plast Reconstr Surg 1969;43:351-65. doi:10.1097/00006534-196904000-00003.

[20] Van Sickels JE, Tiner BD. Midface and periorbital osteotomies. Atlas Oral Maxillofac Surg Clin North Am 1993;1:71-85.

[21] Malagón-Hidalgo H-O, Vilchis-López R, González-Chapa D-R, Silva-Suárez R-A, García-Cano E, Lastiri-Barrios J-L, et al. Le Fort II Osteotomy and Modified Technique Presentation. J Craniofac Surg 2018;29:1406-11. doi:10.1097/SCS.0000000000004760.

[22] Nout E, Cesteleyn LLM, van der Wal KGH, van Adrichem LNA, Mathijssen IMJ, Wolvius EB. Advancement of the midface, from conventional Le Fort III osteotomy to Le Fort III distraction: review of the literature. Int J Oral Maxillofac Surg 2008;37:781-9. doi:10.1016/j.ijom.2008.04.006.

[23] Marchac D, Arnaud E. Midface surgery from Tessier to distraction. Childs Nerv Syst ChNS Off J Int Soc Pediatr Neurosurg 1999;15:681-94. doi:10.1007/s003810050458.

[24] Watanabe K, Kuroda S, Takahashi T, Kijima T, Torikai K, Moriyama K, et al. Segmental distraction osteogenesis with modified LeFort II osteotomy for a patient with craniosynostosis. Am J Orthod Dentofac Orthop Off Publ Am Assoc Orthod Its Const Soc Am Board Orthod 2012;142:698709. doi:10.1016/j.ajodo.2012.07.007.

[25] Hindin DI, Muetterties CE, Lee JC, Kumar A, Kawamoto HK, Bradley JP. Internal Distraction Resulted in Improved Patient-Reported Outcomes for Midface Hypoplasia. J Craniofac Surg 2018;29:139-43. doi:10.1097/SCS.0000000000004109.

[26] Tong H, Liu L, Tang X, Song T, Yin N, Zhang Z, et al. Midface Distraction Osteogenesis Using a Modified External Device With Elastic Distraction for Crouzon Syndrome. J Craniofac Surg 2017;28:1573-7. doi:10.1097/SCS.0000000000003377. 
Legends of figures :

Figure 1a and 1b: supra apical maxillary hypoplasia

Figure 2a and 2b: Nasomaxillary hypoplasia

Figure 3: Total mid facial hypoplasia

Figure 4: Quadrangular Lefort II osteotomies

Figure 5: Peroperative vue Quadrangular Lefort II osteotomies

Figure 6a and 6b: CT scan Quadrangular Lefort II osteotomies

Figure 7a and 7b: Aesthetic result of a Lefort III advancement osteotomy in a Crouzon syndrome

Figure 8: Peroperative vue of a Lefort III advancement osteotomy in a Crouzon syndrome

Figure 9 : CT scan Lefort III osteotomy-distraction osteogenesis

Figure 10: Different types of modified Lefort III osteotomies

Figure 11a and 11b: Post-operative radiological results of simultaneous modified LeFort III/LeFort I osteotomies 


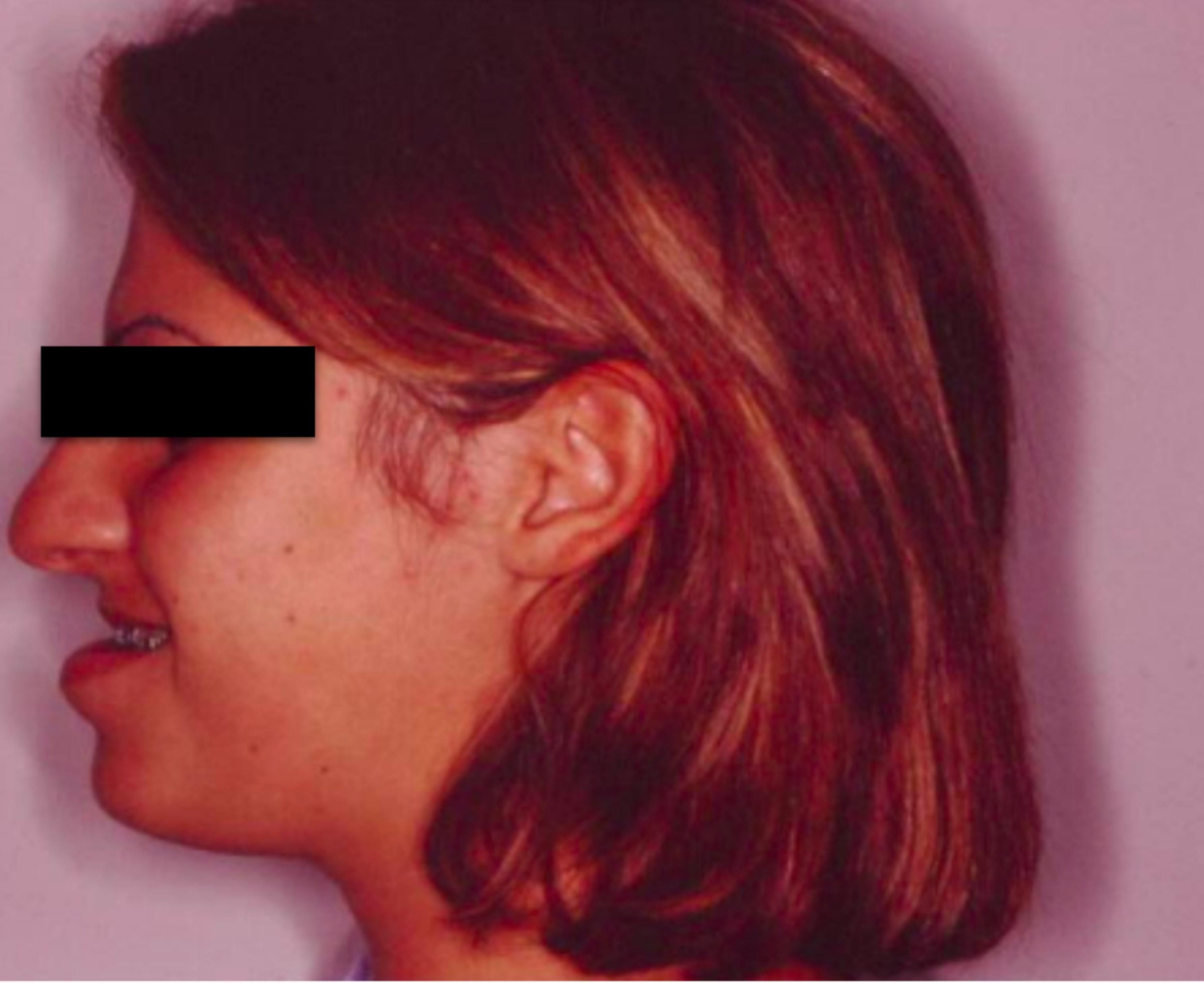




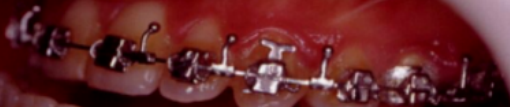

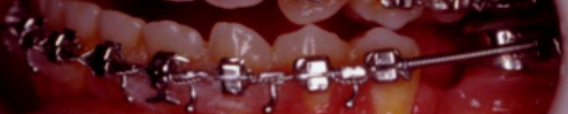

$$
\begin{aligned}
& \text {. } 2 \text { : } 4 \text { ? } b \text { ? }
\end{aligned}
$$

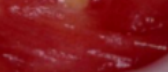




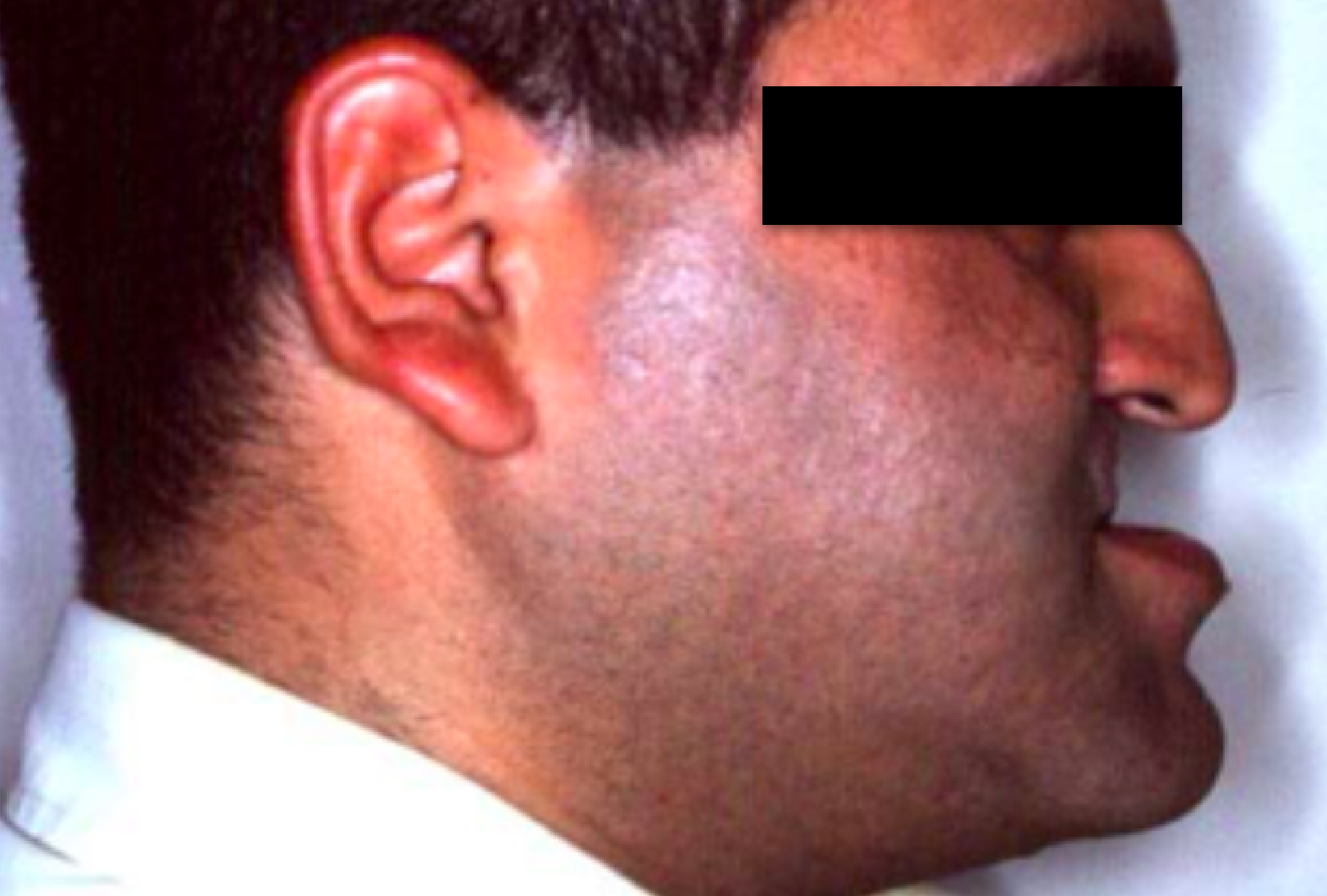




\section{1}

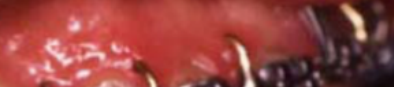

(5)

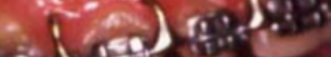

$\sin \frac{10}{10}$

inces

$+1$.

3,

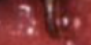
10

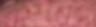

$$
\begin{aligned}
& \text { (n) } k \text {. e } \\
& -0^{\circ}
\end{aligned}
$$

in

9

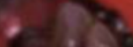

$2,3.4,2$ in 3 is , 12,19

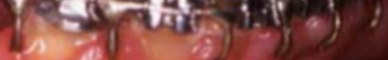




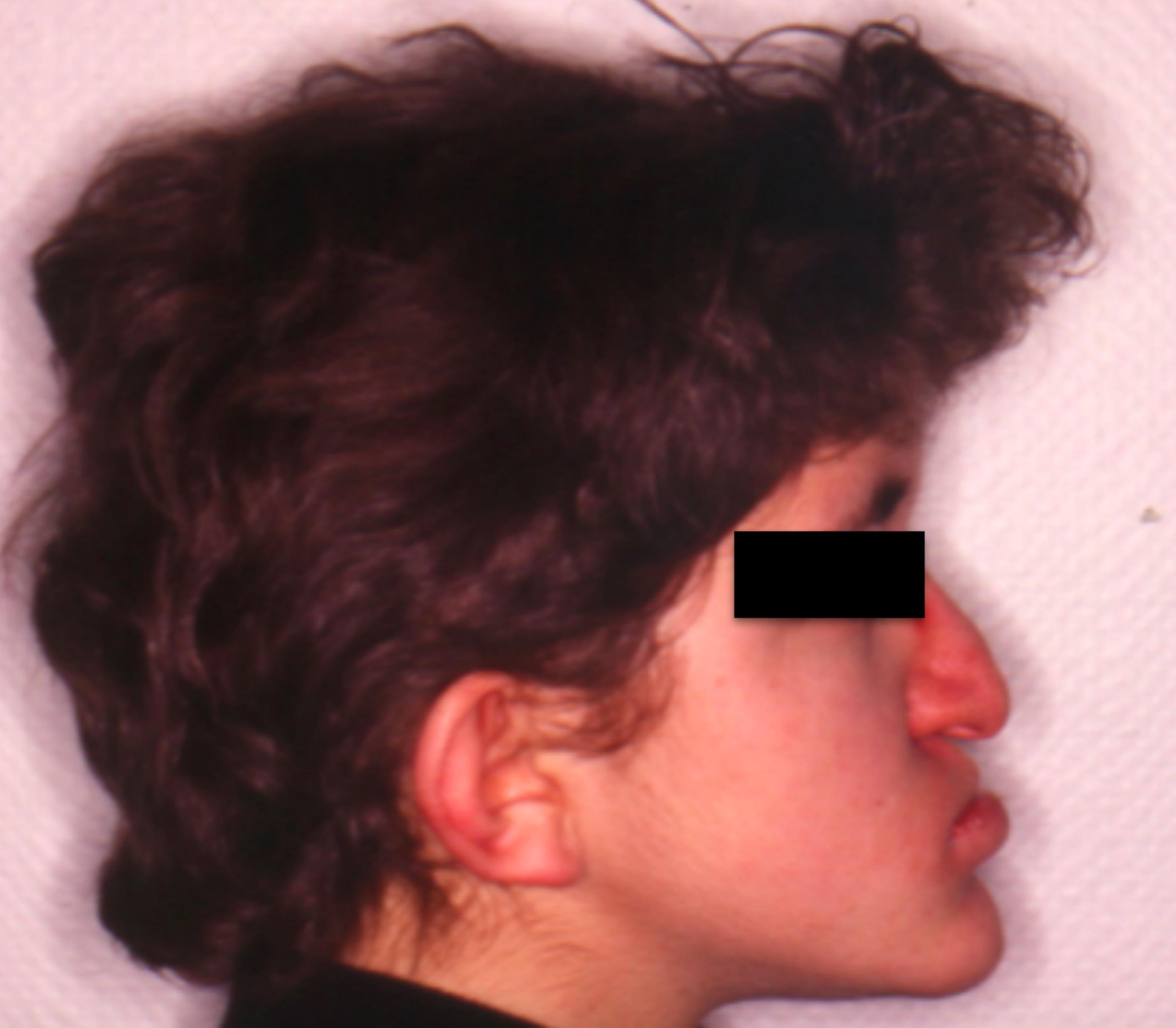



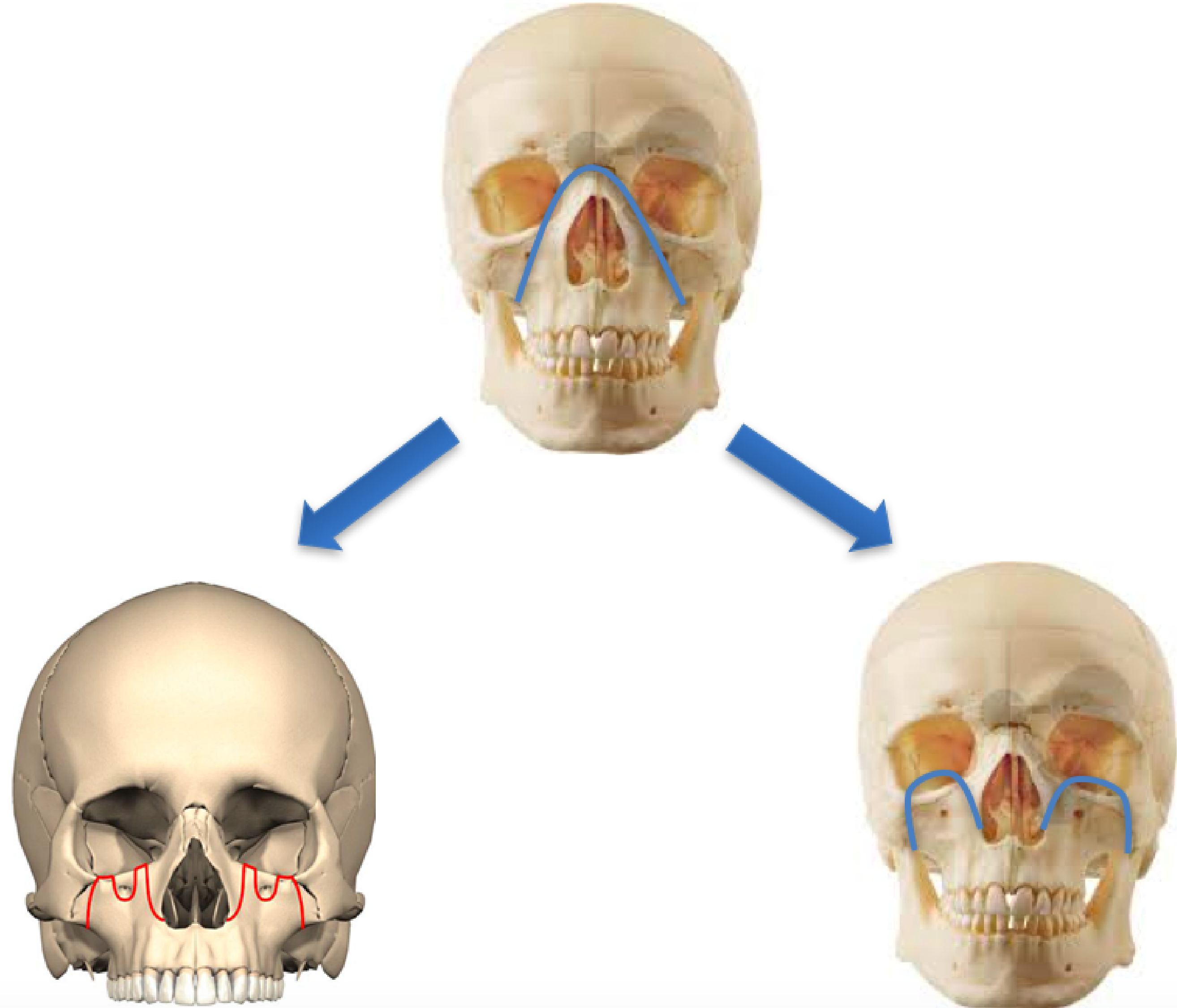


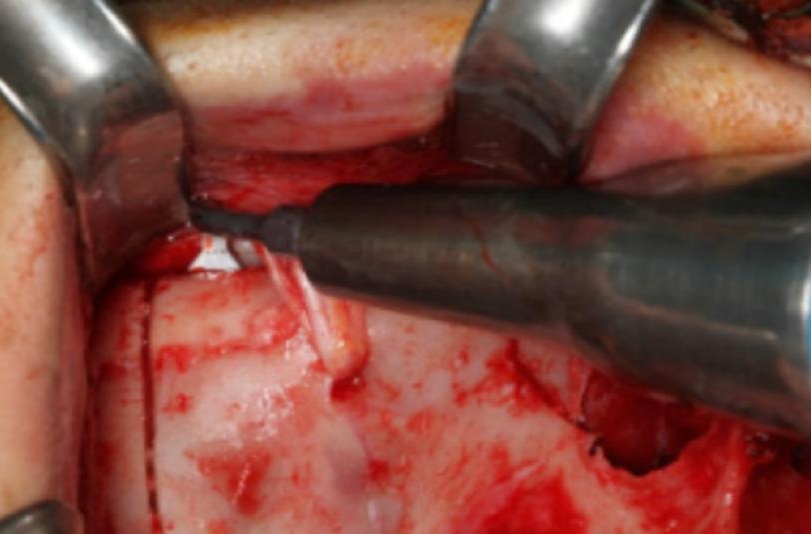




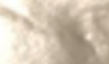




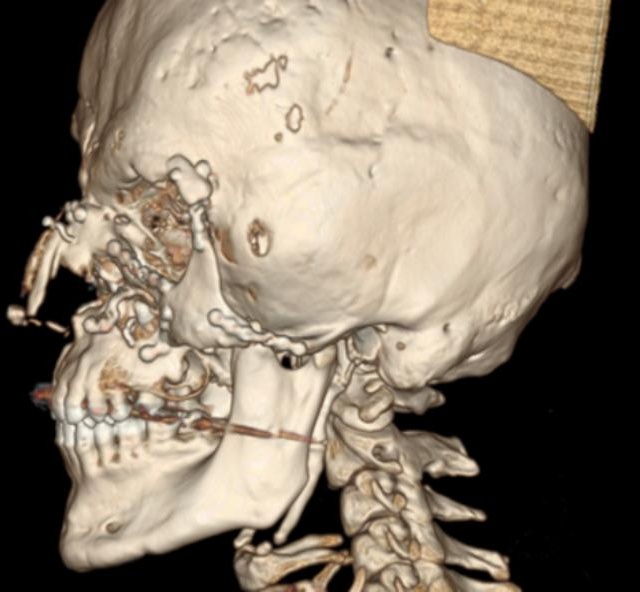




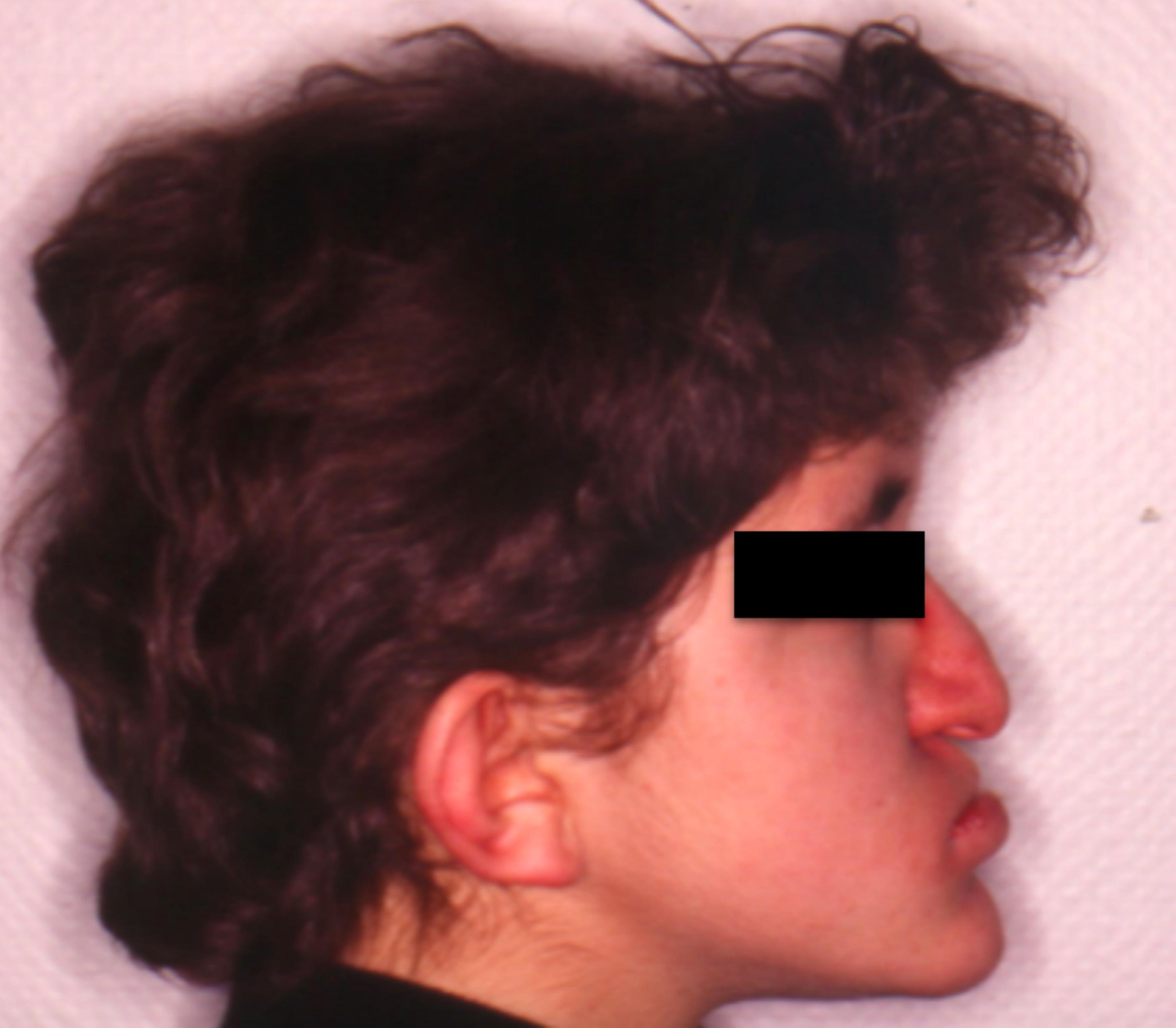




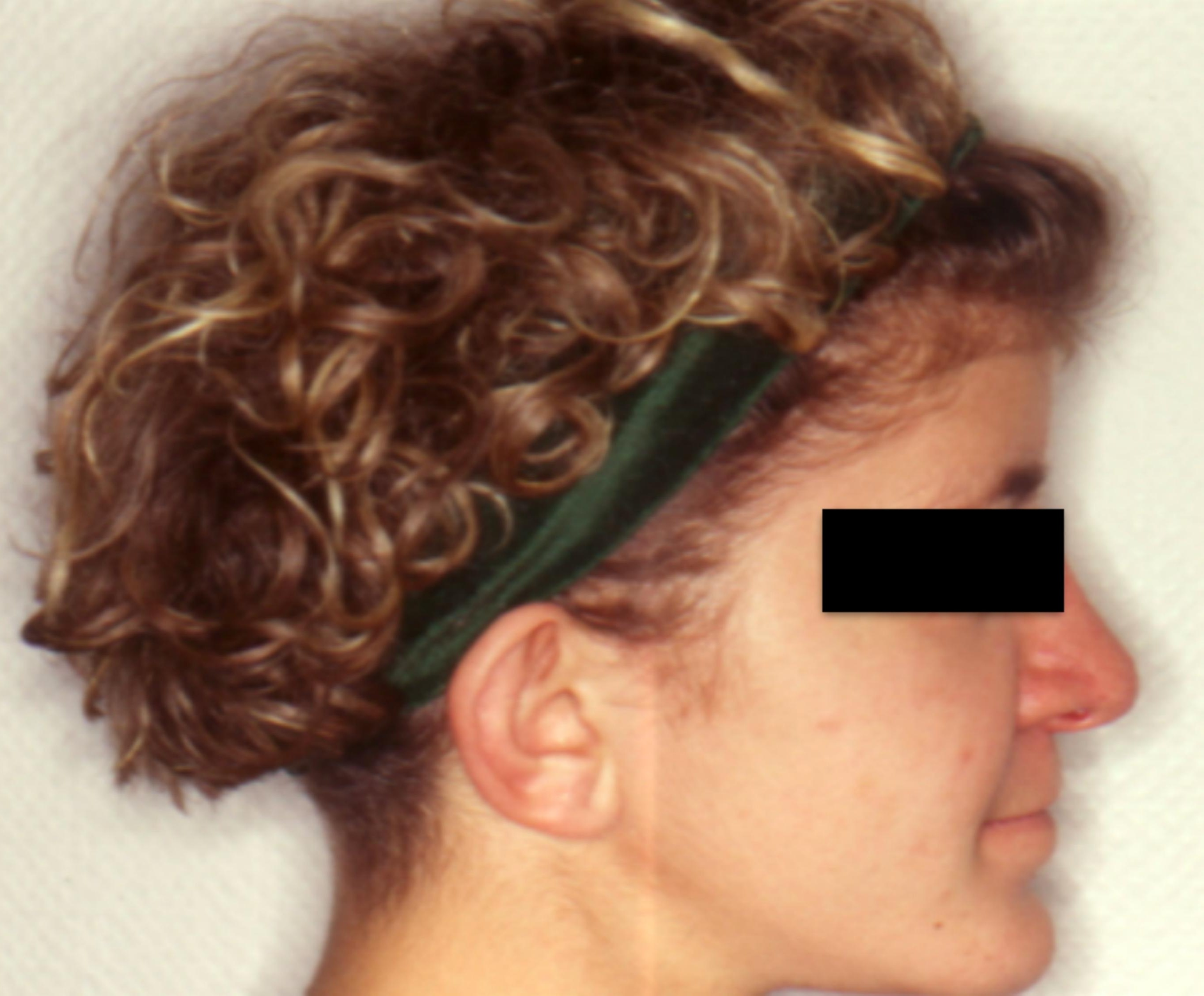




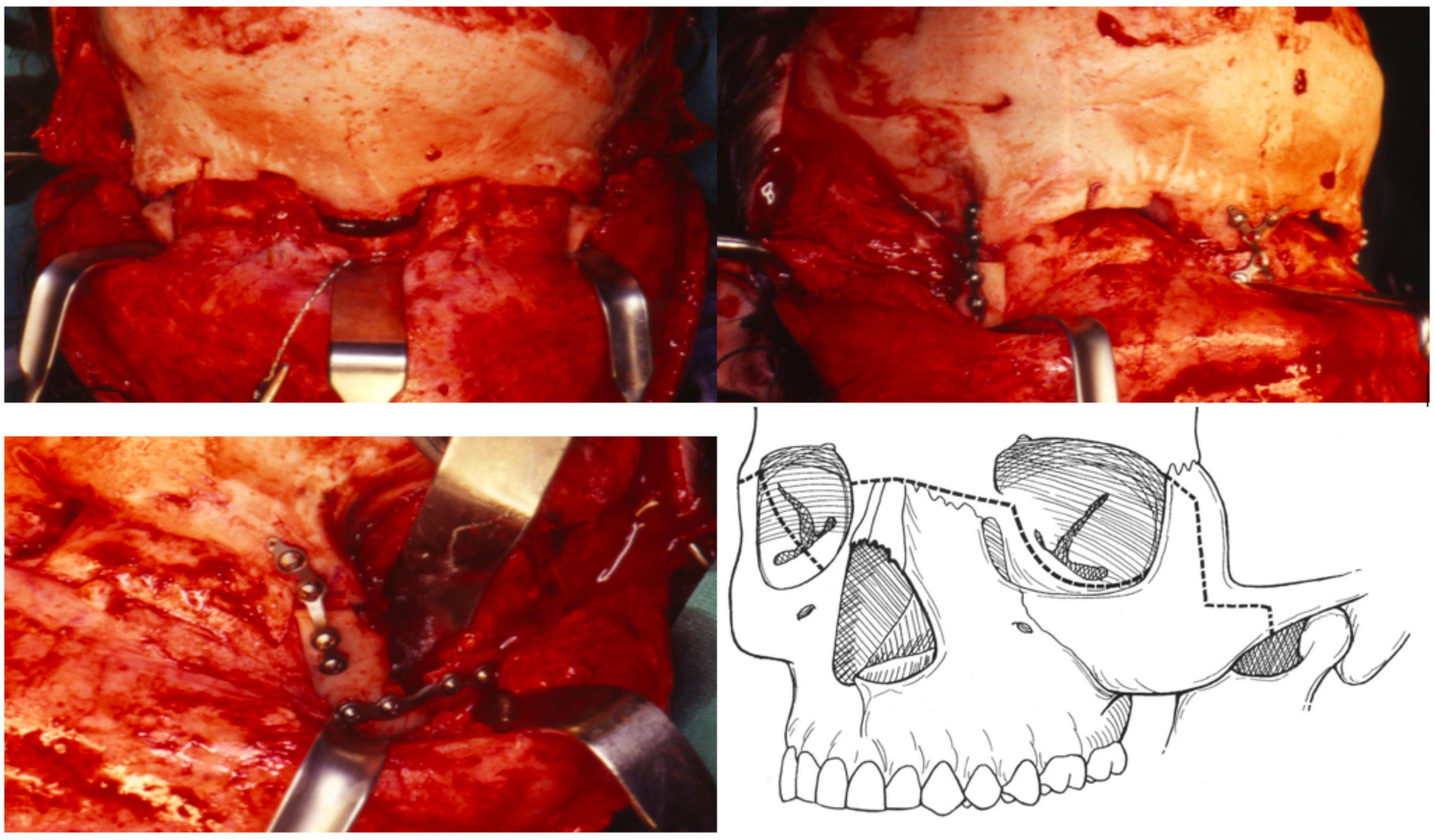




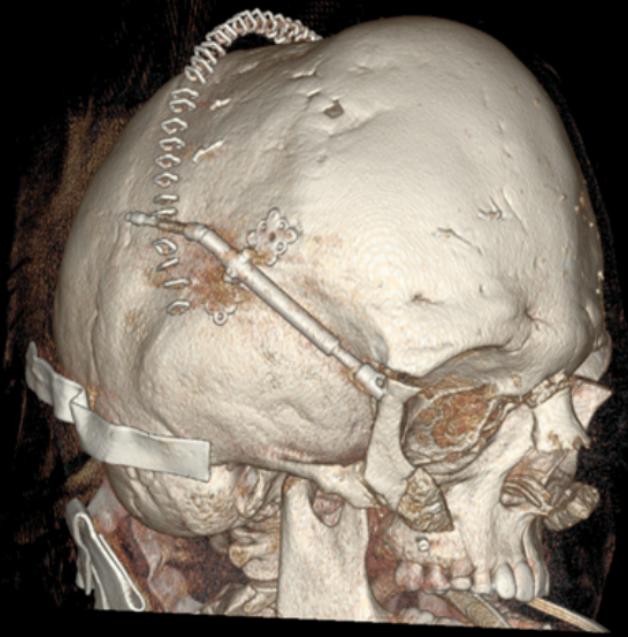




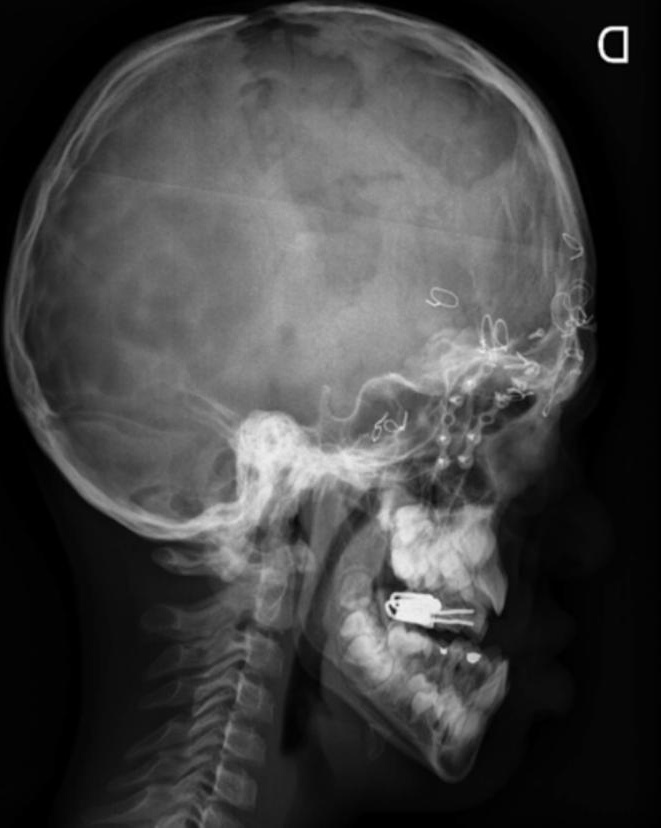




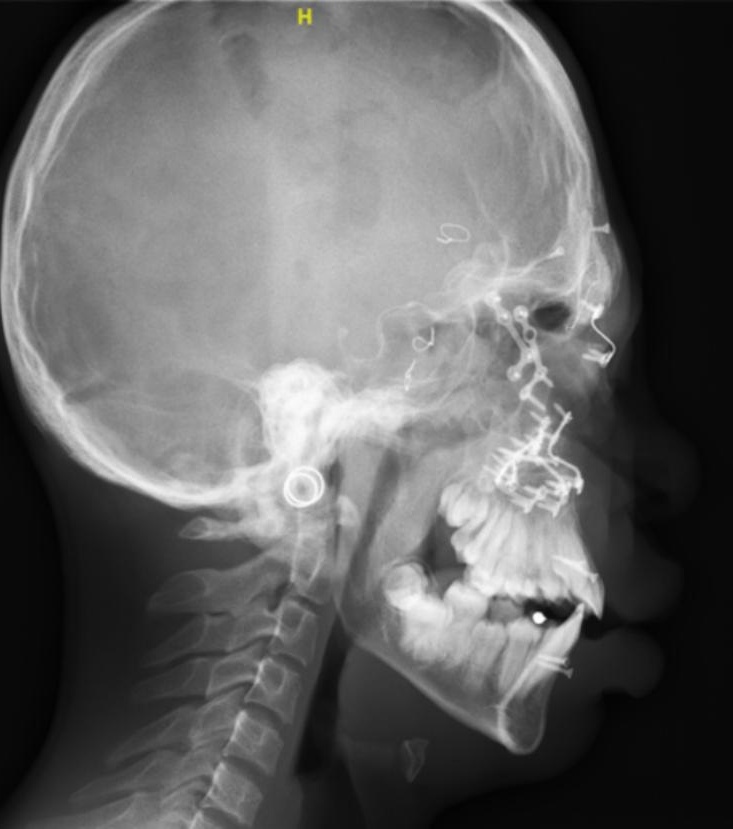

